ARTICLE

\title{
Combustible ice mimicking behavior of hydrogen- bonded organic framework at ambient condition
}

\author{
Yang Wang ${ }^{1}$, Xudong Hou ${ }^{1}$, Congyan Liu' ${ }^{1}$ Mohamed K. Albolkany (1) ${ }^{1}$, Yan Wang ${ }^{1}$, Niannian Wu', \\ Chunhui Chen ${ }^{1} \&$ Bo Liu (iD ${ }^{1 凶}$
}

Adsorption of guest molecules by porous materials proceeds in a spontaneous exothermic way, whereas desorption usually requires external energy input as an endothermic process. Reducing such energy consumption makes great sense in practice. Here we report the reversible and automatic methanol $(\mathrm{MeOH})$ adsorption/release in an ionic hydrogen-bonded organic framework (iHOF) constructed from guanidinium cation and borate anion ([B $\left.\left(\mathrm{OCH}_{3}\right)_{4}\right]_{3}\left[\mathrm{C}\left(\mathrm{NH}_{2}\right)_{3}\right]_{4} \mathrm{Cl} \bullet 4 \mathrm{CH}_{3} \mathrm{OH}$, termed Gd-B) at ambient condition. The metastable Gd$\mathrm{B}$ automatically releases all sixteen $\mathrm{MeOH}$ molecules (63.4 wt\%) via desorption and tetramethyl borate hydrolysis at ambient atmosphere and the structure can be recovered when reexposed to $\mathrm{MeOH}$ vapor or liquid, mimicking combustible ice behavior but at ambient condition. Reversible capture/release of four guest $\mathrm{MeOH}$ molecules is also realized without destroying its crystal structure. The combustible Gd-B paves a way for exploring metastable iHOF materials as carrier for alternative energy source and drug delivery etc.

\footnotetext{
${ }^{1}$ Hefei National Laboratory for Physical Sciences at the Microscale, Fujian Institute of Innovation of Chinese Academy of Sciences, School of Chemistry and Materials Science, University of Science and Technology of China, Hefei, Anhui 230026, China. ${ }^{\varpi}$ email: liuchem@ustc.edu.cn
} 
$\mathrm{N}$ atural gas hydrate (NGH) or combustible ice, a potentially alternative energy source in place of conventional coal and oil, is receiving growing attention to address the existing energy crisis ${ }^{1,2}$. In $\mathrm{NGH}$, gas molecules (primarily methane) are trapped in solid water with a cage crystal structure under low temperature and high pressure ${ }^{3-5}$, which is prone to collapse and release the trapped gas component under increasing temperature and/or reduced pressure (Fig. 1a). The recharge of methane in water that denotes the formation of $\mathrm{NGH}$, is desirable but challenging as harsh condition are of necessity $\left(<10^{\circ} \mathrm{C}\right.$ and $>30 \mathrm{~atm})^{6,7}$. Nevertheless, it is highly revelatory for us to mimic this process for storing energy-containing materials, via molecule inclusion during host formation and release when host breaking in mild condition, for example, ambient atmosphere. For cycling usage, the broken host materials should revert with recharge of released guest molecules in a facial and economic way, which is impracticable for NGH.

A diverse class of porous materials, including carbon, zeolites, metal organic frameworks (MOFs), covalent organic frameworks (COFs), and porous molecular crystals etc., have been developed to function as sorbents for gas storage owing to their tunable structures, pores sizes, and high surface area ${ }^{8-12}$. Although they exhibited excellent gas-storage capability, the storage/release mechanism is totally distinct from the process in NGH (Fig. 1). Specifically, these porous materials adsorb guest molecules by virtue of high surface area and thus strong surface affinity, whereas release of guest molecules, especially for volatile organic compounds, often needs extra energy (heating and/or vacuuming), as shown in Fig. 1b. In contrast, the methane molecules release from $\mathrm{NGH}$ is furious and thus out of control at ambient condition.

Although a variety of strategies on enhancing the adsorptive capacity have been extensively proposed, facial control on release of adsorbed molecules is little explored. In order to achieve controllable and reversible adsorption/release of guest molecules, there are two possible pathways: either adjusting the guest-host interaction or controlling the reversible framework transformation based on guest release and capture. The synergy between the two pathways can provide better control over the ad/desorption behavior. Some recent studies focused on the control of the guest-host interactions. For example, Kim et al. reported a $\mathrm{Zr}$-MOF-based device to achieve water desorption from MOF with a low solar energy input of $1 \mathrm{~kW} \mathrm{~m}^{-212}$. Cadiau et al. developed a fluorinated MOF with a periodic array of open metal coordination sites and fluorine moieties within the onedimensional channel, which releases adsorbed water at relatively moderate temperature $\left(\sim 105^{\circ} \mathrm{C}\right)$, about half the energy input for commonly used desiccants ${ }^{13}$. In terms of MOF and COF studies, intensive attention has been paid to improve their stability. Nevertheless, most porous frameworks collapsing by thermodynamic and/or chemical ways cannot be recovered, which renders the second strategy inaccessible.

Hydrogen-bond (H-bond) assisted supermolecular assembly shows great structural flexibility owing to the moderate strength of H-bonds, which could be ideal candidate for controllable capture/release of guest molecules at mild condition ${ }^{14-17}$. The past decades have witnessed the emerging progress of hydrogenbonded organic frameworks (HOFs) constructed via intermolecular $\mathrm{H}$-bonds ${ }^{18-23} \mathrm{H}$-bond originated from electrostatic attraction is readily formed among adjacent organic molecules bearing electronegative groups, which does not ask for extra energy for reaction ${ }^{24}$. Therefore, HOFs can be prepared via dissolving and recrystallizing of organic molecules, while the weak noncovalent interaction of $\mathrm{H}$-bond renders most HOFs fragile, getting collapsed upon removal of guest molecules ${ }^{18}$. Only few HOFs show permanent porosity for adsorption ${ }^{24-26}$.

In addition to the reported HOFs comprising neutral organic molecules ${ }^{18}$, another type of HOFs is constructed from cations and anions. Herein, these charge-assisted frameworks are denoted as ionic HOFs (iHOFs), in which electrostatic attraction between cations and anions plays a vital role for iHOF assembling to strengthen the stability of established framework, beyond H-bonding and Van der Waals force ${ }^{17,27,28}$ Guanidinium cation, coupled with sulfonate $\left[\mathrm{SO}_{4}\right]^{2-}$, has been adopted to construct $\mathrm{iHOFs}^{29-31}$. In 2005, Abrahams et al. reported the synthesis and structural characterization of $\mathrm{iHOF}\left[\mathrm{B}\left(\mathrm{OCH}_{3}\right)_{4}\right]_{3}[\mathrm{C}$

a
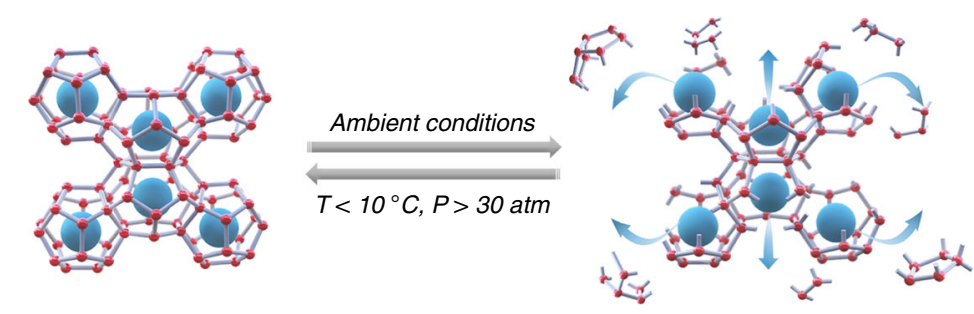

b
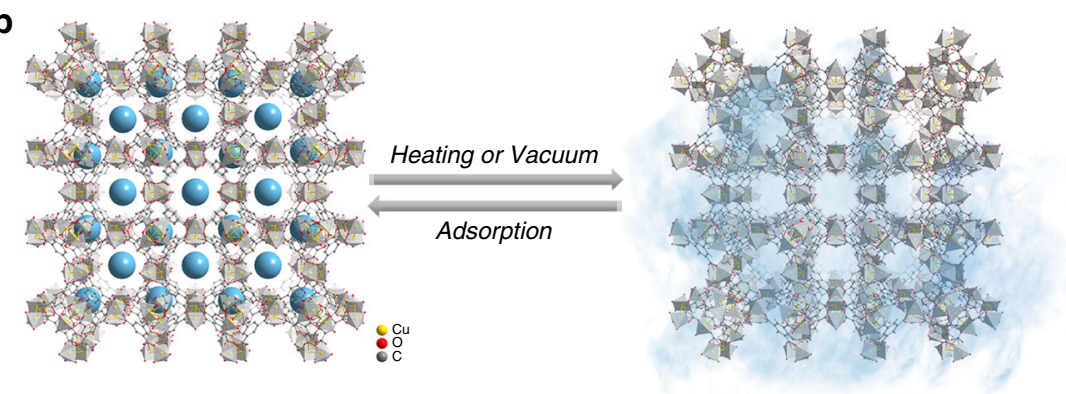

Fig. 1 Guest capture/release mechanism. a Methane molecules (blue balls) stored within water cage (constructed by red balls and gray sticks) and released (denoted by blue arrows) after cage collapse under different condition, the typical hydrate structure I comprising large $5^{12} 6^{2}$ (twelve pentagonal and two hexagonal faces) and small $5^{12}$ cages is taken for illustration. b Methane molecules (blue balls) stored in MOF (HKUST-1 as an example) cavities release upon applying external energy (heating or vacuum). Orange, red, gray balls, and light gray tetrahedrons denote $\mathrm{Cu}, \mathrm{O}, \mathrm{C}$ atoms, and the subunits within HKUST-1, respectively. $\mathrm{H}$ atoms are omitted for clarity. The blue smog denotes the methane gas atmosphere. 
a

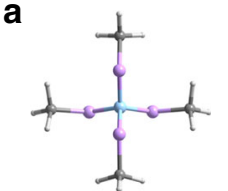

C

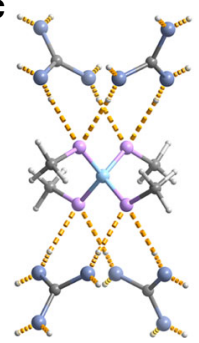

b
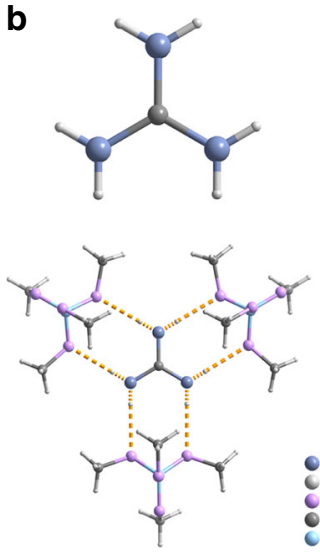

d

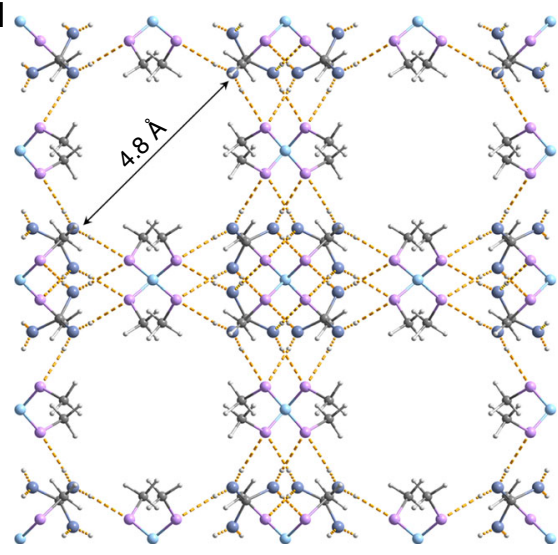

Fig. 2 Crystal structure of Gd-B. a Borate ester anion. $\mathbf{b}$ Guanidinium cation. c H-bond linking (denoted as dashed yellow line) between a and $\mathbf{b}$. d Gd-B framework comprising borate ester anion and guanidinium cation via $\mathrm{H}$-bond linking (highlighted by dashed yellow line, disordered $\mathrm{Cl}^{-}$and guest $\mathrm{MeOH}$ molecules are omitted for clarity). The Gd-B framework features a pore size of $4.8 \AA$ that enables the inclusion of $\mathrm{MeOH}$ molecules. Grayish blue, light gray, pink, gray, and pale blue balls denote $\mathrm{N}, \mathrm{H}, \mathrm{O}, \mathrm{C}$, and $\mathrm{B}$ atoms, respectively.

$\left.\left(\mathrm{NH}_{2}\right)_{3}\right]_{4} \mathrm{Cl} \cdot 4 \mathrm{CH}_{3} \mathrm{OH}$ (termed $\left.\mathrm{Gd}-\mathrm{B}\right)^{31}$. In this work, we explore the reversible structural transformation of $\mathrm{Gb}-\mathrm{B}$ upon $\mathrm{MeOH}$ capture and release without extra energy input, which mimics $\mathrm{NGH}$ in terms of the adsorption-release behavior of guest molecules while differs in operation conditions (ambient atmosphere vs. harsh condition) and adsorbates (methanol vs. methane). Similar with combustible ice, we obtain combustible Gd-B, in which $\mathrm{MeOH}$ can be directly released into air for lighting at ambient condition.

\section{Results}

General information and XRD analyses of Gd-B. Gd-B was prepared according to the reported procedures ("Methods" section and Supplementary Table 1$)^{31}$. The borate ester anion and guanidinium cation (Fig. 2a, b) are assembled via electrostatic interaction and $\mathrm{H}$-bond into framework. Each borate ester anion is connected with four guanidinium cations via H-bond, while each guanidinium cation bridges three borate ester anions (N-H-O, N-O distance: $2.914 \AA$, angle: $174.68^{\circ}$ ) (Fig. 2c). The spatial extension of these $(3,4)$-connected units renders a threedimensional H-bonded framework $((63)(6284)$ or boracite topology) with pore size of $4.8 \AA$ (Fig. $2 \mathrm{~d}$ ). As shown in Fig. 3a, the PXRD patterns indicate that the crystal structure of asprepared Gd-B keeps good consistency with that of simulated from single-crystal XRD data. And elemental analysis (Supplementary Table 2) reveals that fresh Gd-B matches well with the formula $\left[\mathrm{B}\left(\mathrm{OCH}_{3}\right)_{4}\right]_{3}\left[\mathrm{C}\left(\mathrm{NH}_{2}\right)_{3}\right]_{4} \mathrm{Cl} \cdot 4 \mathrm{CH}_{3} \mathrm{OH}$. We found that transparent regular tetrahedron of freshly prepared Gd-B turned into white powder when exposing in air (Supplementary Fig. 1). Specifically, the fresh Gd-B gradually lost its own crystallinity upon exposure in air, i.e., for $6 \mathrm{~h}$ (Supplementary Fig. 2). Prolonged exposure led to structural transformation and produced a new phase (for example, air drying for $24 \mathrm{~h}$ ) totally different from fresh Gd-B (Fig. 3a). We did not observe further phase transformation by exposure in air up to $72 \mathrm{~h}$, indicating the favorable stability of the transformed powder phase (Supplementary Fig. 2). Importantly, when this powder (termed air-dried Gd-B) was exposed to $\mathrm{MeOH}$ vapor, for example $24 \mathrm{~h}$, the structure of $\mathrm{Gd}-\mathrm{B}$ can be recovered (Fig. 3a). This reversible structural transformation can also be realized by directly dissolving the powder in liquid $\mathrm{MeOH}$ and recrystallizing via $\mathrm{MeOH}$ evaporation (Supplementary Fig. 3). All these processes took place at ambient condition. Also, the air-dried Gd-B can be readily dissolved in $\mathrm{H}_{2} \mathrm{O}$ and crystallized into guanidinium tetraborate dihydrate
$\left(\left[\mathrm{C}\left(\mathrm{NH}_{2}\right)_{3}\right]_{2}\left[\mathrm{~B}_{4} \mathrm{O}_{5}(\mathrm{OH})_{4}\right] \cdot 2 \mathrm{H}_{2} \mathrm{O} \text {, Supplementary Fig. } 4\right)^{32}$, which was stable in air atmosphere but turned into Gd-B again when dissolving and recrystallizing in $\mathrm{MeOH}$ (Supplementary Methods and Supplementary Fig. 5). These findings illustrate that Gd-B undergoes reversible structure transformation upon release and re-adsorption of $\mathrm{MeOH}$. Furthermore, the $\mathrm{H}$-bonded framework of Gd-B can be maintained upon vacuum drying of both fresh Gd-B (Supplementary Fig. 6) and recovered Gd-B (Fig. 3a).

NMR analyses of Gd-B. We further carried out the ${ }^{1} \mathrm{H}-\mathrm{NMR}$ and ${ }^{13} \mathrm{C}-\mathrm{NMR}$ analyses over Gd-B samples. As shown in Fig. 3b, fresh Gd-B features two peaks at $3.17 \mathrm{ppm}$ and $4.04 \mathrm{ppm}$, which are assigned to hydrogen from the $-\mathrm{CH}_{3}$ and $-\mathrm{OH}$ groups in $\mathrm{MeOH}$, respectively. Note that the detection of $-\mathrm{NH}_{2}$ linked groups within the structure is not available using ${ }^{1} \mathrm{H}-\mathrm{NMR}$ analysis, owing to the existence of active protons that may drift over a wide range of chemical shifts ${ }^{33}$. After vacuum drying for $24 \mathrm{~h}$, in spite of removing $\mathrm{MeOH}$ guest molecules, the same ${ }^{1} \mathrm{H}$ chemical shifts are evidenced from the $-\mathrm{OCH}_{3}$ group in borate ester (Fig. 2a). Further ${ }^{13} \mathrm{C}-\mathrm{NMR}$ tests (Fig. 3c) confirm the existence of the ester group $-\mathrm{OCH}_{3}$, as the peak at $48.59 \mathrm{ppm}$ can be detected even after vacuum drying over fresh Gd-B for $1 \mathrm{~h}$. However, this peak indicative of $-\mathrm{OCH}_{3}$ is absent in air-dried Gd-B samples, suggesting the decomposition of the framework upon interaction with moisture in ambient atmosphere. When the air-dried Gd-B was exposed to $\mathrm{MeOH}$ vapor for $24 \mathrm{~h}$, reversible structural transformation was observed, as indicated by the peak at $48.59 \mathrm{ppm}$, which is identical with that of fresh Gd-B. As for the ${ }^{1} \mathrm{H}-\mathrm{NMR}$ spectra of air-dried Gd-B samples, the chemical shift at $\sim 3.17$ ppm gets continuously weakened and finally disappears with prolonging exposure in air for drying (Fig. 3d). All these results match well with XRD analyses.

Structural transformation of Gd-B. Combined with Gd-B crystal structure, XRD, and NMR analyses, we could come to a convincing interpretation of the structure transformation during its exposure in air and structural restoration as displayed in Fig. 4. Fresh Gd-B firstly loses the accommodated $4 \mathrm{MeOH}$ molecules at the beginning of exposure in air; subsequently, borate ester anion of $\left[\mathrm{B}\left(\mathrm{OCH}_{3}\right)_{4}\right]^{-}$gets hydrolyzed by moisture and further releases $12 \mathrm{MeOH}$ molecules (Supplementary Fig. 7). Upon exposure to $\mathrm{MeOH}$, the residual white powder (air-dried Gd-B) experiences the formation of borate ester to re-build the Gd-B framework and adsorption of $\mathrm{MeOH}$ to fill in the cavity, giving rise to the 

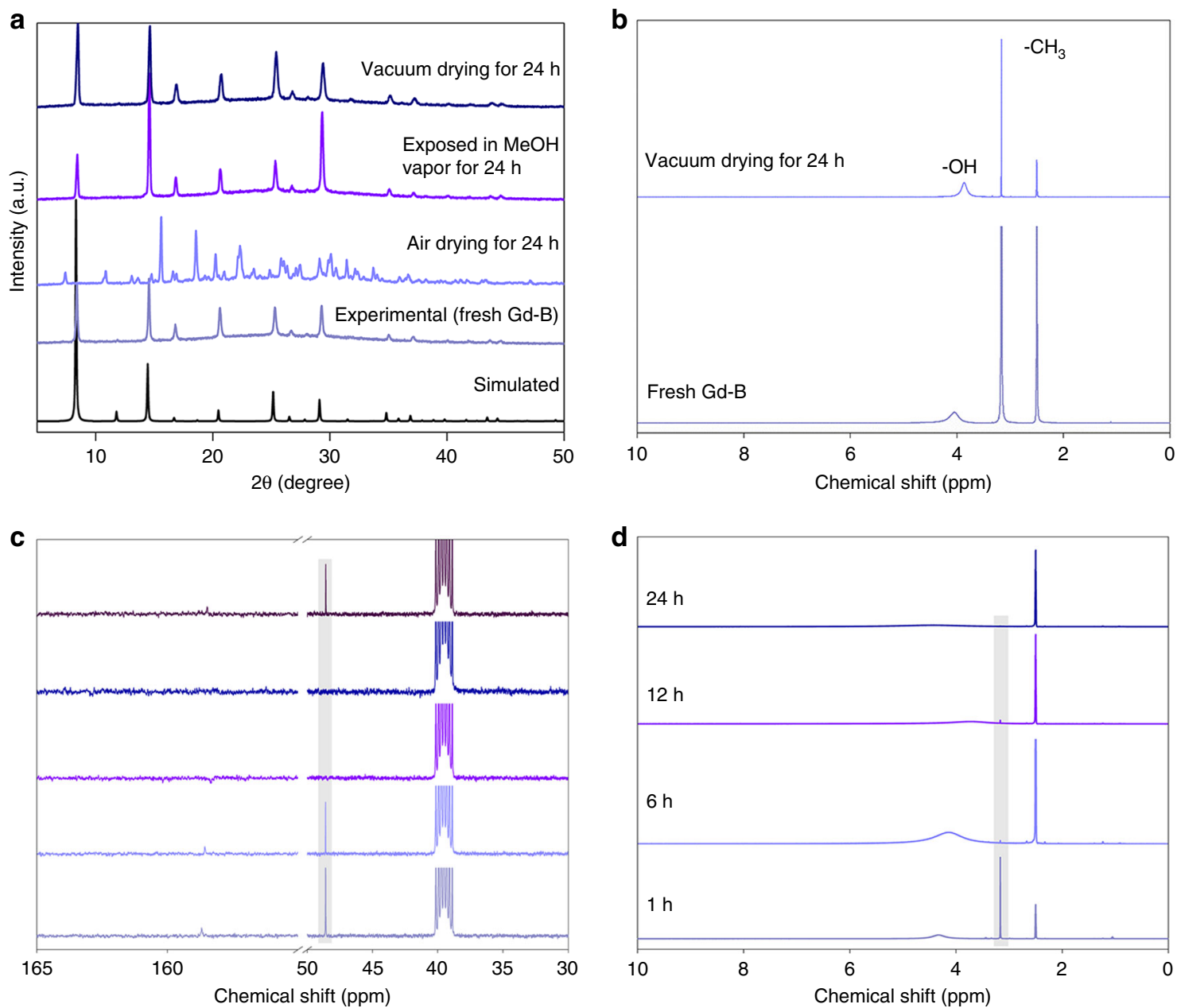

Fig. 3 Characterizations of structural evolution of Gd-B. a Powder X-ray diffraction (PXRD) patterns of fresh Gd-B underwent successive treatments under different conditions. Specifically, fresh Gd-B was firstly exposed in air atmosphere for $24 \mathrm{~h}$, the dried powder sample was then exposed in MeOH vapor for $24 \mathrm{~h}$, followed by vacuum drying for $24 \mathrm{~h}$. b ${ }^{1} \mathrm{H}-\mathrm{NMR}$ spectra of fresh Gd-B and Gd-B dried under vacuum for $24 \mathrm{~h}$. c ${ }^{13} \mathrm{C}-\mathrm{NMR}$ spectra of fresh $\mathrm{Gd}-\mathrm{B}, \mathrm{Gd}-\mathrm{B}$ dried under vacuum for $1 \mathrm{~h}$, air-dried $\mathrm{Gd}-\mathrm{B}$ and then vacuum dried for $1 \mathrm{~h}$, air-dried $\mathrm{Gd}-\mathrm{B}$, and then exposed in $\mathrm{MeOH}$ vapor for $24 \mathrm{~h}$ (from bottom to top). $\mathbf{d}^{\mathrm{T}} \mathrm{H}$-NMR spectra of fresh Gd-B under air drying for different time. $\mathrm{d}_{6}$-DMSO was utilized for these characterizations.

restoration of Gd-B crystal structure (path 1 in Fig. 4). Alternatively, the restoration process can be facilitated by two-step recrystallization, benefiting from the facial transformation among $\left[\mathrm{B}(\mathrm{OH})_{4}\right],\left[\mathrm{B}_{4} \mathrm{O}_{5}(\mathrm{OH})_{4}\right]$ (Supplementary Fig. 4) and $\left[\mathrm{B}\left(\mathrm{OCH}_{3}\right)_{4}\right]$ groups (path 2 in Fig. 4). It is also evidenced that vacuum treatment can only remove the $\mathrm{MeOH}$ existing as a guest molecule and Gd-B framework structure remains intact (Supplementary Fig. 6). We experimentally confirm the Gd-B structure collapse and reconstruction with $\mathrm{MeOH}$ release and capture, which mimics the NGH behavior for energetic molecules storage, but under mild condition without extra energy input.

Adsorption and release behavior of Gd-B. As $\mathrm{MeOH}$ in $\mathrm{Gd}-\mathrm{B}$ $\mathrm{HOF}$ can be readily released in air, we directly activated fresh Gd$B$ sample via vacuum at room temperature for nitrogen isotherm measurement. Nitrogen ad/desorption at $77 \mathrm{~K}$ reveals a typical type-I isotherm with a specific surface area of $257 \mathrm{~m}^{2} \mathrm{~g}^{-1}$ (Fig. 5a), and Gd-B exposed to $\mathrm{N}_{2}$ atmosphere at varied pressure during the test signifies its stability in inert gas, where structural transformation into air-dried Gd-B will not take place. The pore size distribution indicates a primary pore size of $\sim 4.85 \AA$ (Supplementary Fig. 8), which is in line with the structural analysis in Fig. 2d. The $\mathrm{H}_{2}$ adsorption amount at $77 \mathrm{~K}$ is determined to be ca. $50 \mathrm{~cm}^{3} \mathrm{~g}^{-1}$. The sample exhibits a $\mathrm{CO}_{2}$ adsorption of ca. $13 \mathrm{~cm}^{3} \mathrm{~g}^{-1}$ at $298 \mathrm{~K}$. The obvious hysteresis is ascribed to the strong interaction between acidic $\mathrm{CO}_{2}$ and the amino group of guanidinium cation in Gd-B; similar hysteresis has also been reported in amino-functionalized MOFs that enhance $\mathrm{CO}_{2}$ adsorption $^{34,35}$.

Encouraged by the reversible structure collapse and restoration of Gd-B upon release and adsorption of $\mathrm{MeOH}$ at ambient condition without extra energy input, $\mathrm{MeOH}$ sorption behaviors are evaluated in more details to reveal these processes and provide guidance for rational design of functional materials as carriers for alternative energy source. Specifically, we collected $\mathrm{MeOH}-$ sorption isotherms over nonporous air-dried Gd-B (Supplementary Fig. 9) at $298 \mathrm{~K}$ for multiple runs (Fig. 5b), where after each run, the sample is online evacuated for activation without exposure to air. For the first run, $\mathrm{MeOH}$ adsorption over airdried Gd-B reaches up to $417 \mathrm{~cm}^{3} \mathrm{~g}^{-1}$, corresponding to $59.6 \mathrm{wt} \%$ of $\mathrm{MeOH}$ in fresh $\mathrm{Gd}-\mathrm{B}$ that contains 16 methoxyl groups. The $\mathrm{MeOH}$ adsorption capability is high among the reported adsorbents, which is comparable with MIL-100 having specific area $>3000 \mathrm{~m}^{2} \mathrm{~g}^{-1}$ (Supplementary Table 3). The result shows little deviation from theoretically calculated value $(63.4 \mathrm{wt} \%)$. It is noted that at initial stage, there is no $\mathrm{MeOH}$ adsorption occurring till the $\mathrm{P} / \mathrm{P}_{0}$ of 0.45 . Subsequently, $\mathrm{MeOH}$ adsorption increases 
a

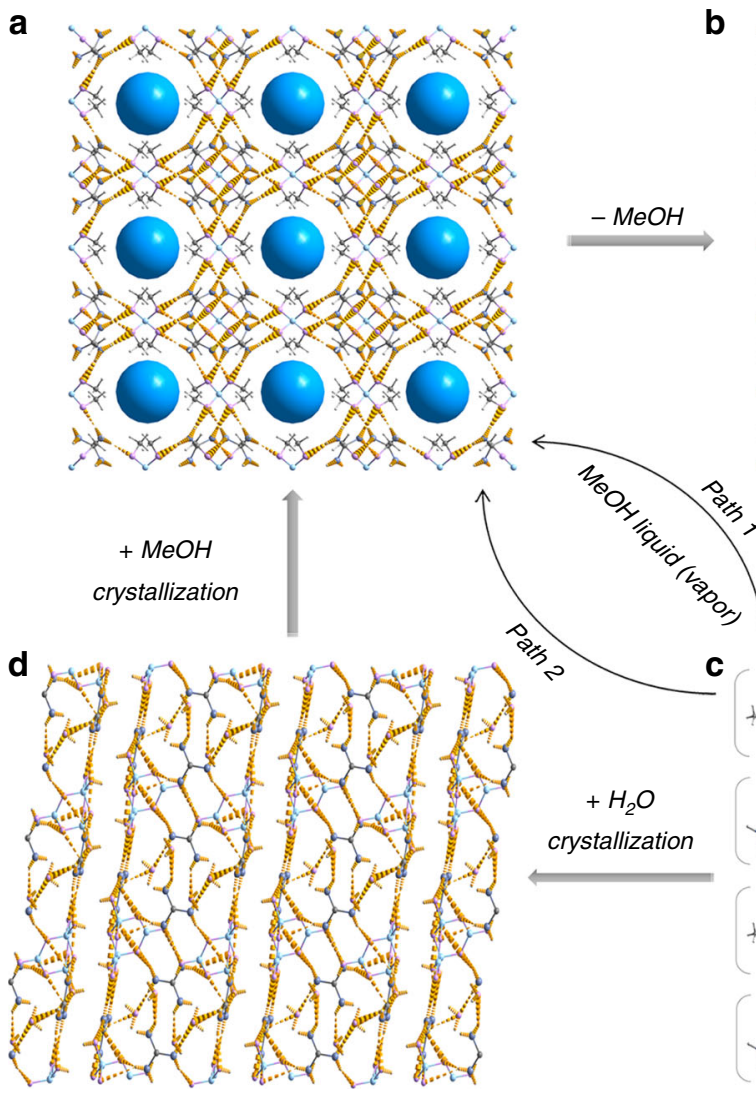

b
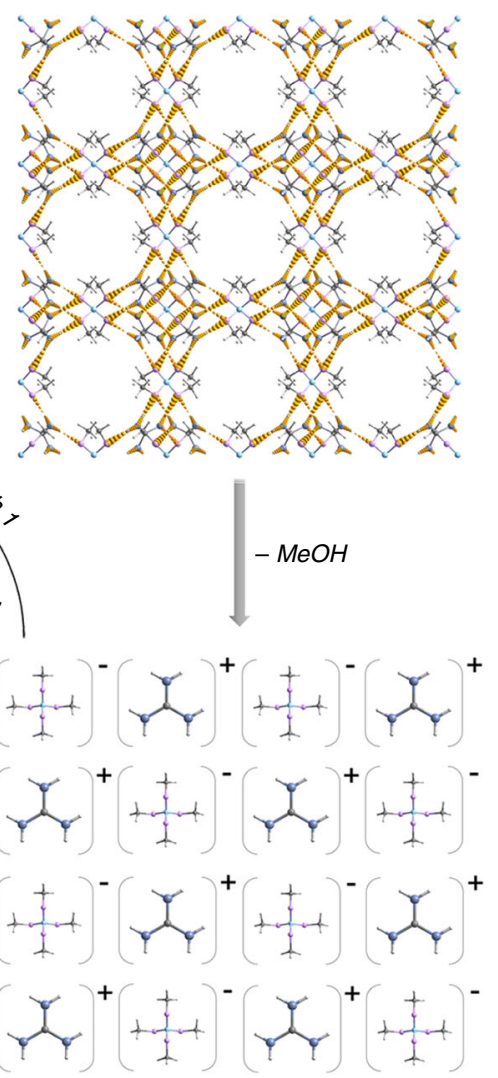

Fig. 4 Structural transformation of Gd-B samples at ambient condition. a-c Fresh Gd-B (a) loses accommodated MeOH (blue balls) molecules (b) upon exposure in air atmosphere, prolonged exposure results in the hydrolysis of borate ester anion of $\left[\mathrm{B}\left(\mathrm{OCH}_{3}\right)_{4}\right]^{-}$by moisture, which further releases twelve

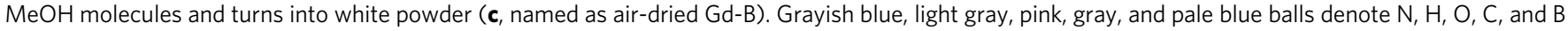
atoms, respectively. The dashed yellow lines denote the $\mathrm{H}$-bond linking. $\mathbf{d}$ Crystal structure of $\left[\mathrm{C}\left(\mathrm{NH}_{2}\right)_{3}\right]_{2}\left[\mathrm{~B}_{4} \mathrm{O}_{5}\left(\mathrm{OH}_{4}\right)_{\bullet} 2 \mathrm{H}_{2} \mathrm{O}\right.$. Two paths are available for the structural restoration of $\mathrm{Gd}-\mathrm{B}$. Typically, air-dried $\mathrm{Gd}-\mathrm{B}$ is exposed in $\mathrm{MeOH}$ liquid or vapor to obtain $\mathrm{Gd}-\mathrm{B}$ (path 1 ); air-dried $\mathrm{Gd}-\mathrm{B}$ is dissolved in $\mathrm{H}_{2} \mathrm{O}$ and recrystallized into $\left[\mathrm{C}\left(\mathrm{NH}_{2}\right)_{3}\right]_{2}\left[\mathrm{~B}_{4} \mathrm{O}_{5}(\mathrm{OH})_{4}\right] \cdot 2 \mathrm{H}_{2} \mathrm{O}$, which is further dissolved and recrystallized in $\mathrm{MeOH}$ to obtain $\mathrm{Gd}-\mathrm{B}$ (path 2).

steeply, indicating a breakthrough point. The adsorption amount of $\sim 117 \mathrm{~cm}^{3} \mathrm{~g}^{-1}\left(0.167 \mathrm{~g} \mathrm{~g}^{-1}\right)$ at breakthrough point that accounts for about $1 / 4$ of the total adsorption amount, corresponding to physically adsorbed four $\mathrm{MeOH}$ molecules in the formula of [B $\left.\left(\mathrm{OCH}_{3}\right)_{4}\right]_{3}\left[\mathrm{C}\left(\mathrm{NH}_{2}\right)_{3}\right]_{4} \mathrm{Cl} \bullet 4 \mathrm{CH}_{3} \mathrm{OH}$. The remaining $3 / 4$ adsorption amount of $\sim 300 \mathrm{~cm}^{3} \mathrm{~g}^{-1}\left(0.429 \mathrm{~g} \mathrm{~g}^{-1}\right)$ is identified at higher relative pressure, corresponding to 12 methoxyl groups on borate ester in Gd-B. However, we realized that physical adsorption cannot be reached prior to Gd-B framework restoration. We carried out the 2 nd run ad/desorption test after vacuum treatment over the air-dried Gd-B. The isotherm indicates that the breakthrough point disappears and the total adsorption amount is decreased to be ca. $\sim 300 \mathrm{~cm}^{3} \mathrm{~g}^{-1}$. Subsequent $3 \mathrm{rd}$ and 4 th runs of ad/desorption also show continuous decrease of $\mathrm{MeOH}$ adsorption amount (Fig. 5b). The $\mathrm{MeOH}$ sorption behavior of the 5th run is almost identical with that in 4th run (Supplementary Fig. 10). Meanwhile, fresh Gb-B treated by vacuum exhibits the almost overlapped sorption isotherm with that of air-dried sample at 5th run (Fig. 5c), with a saturated adsorption amount of $118 \mathrm{~cm}^{3} \mathrm{~g}^{-1}$ and $116 \mathrm{~cm}^{3} \mathrm{~g}^{-1}$, respectively. This is in line with physically adsorbed four $\mathrm{MeOH}$ molecules in Gd-B.

As demonstrated by the XRD results (Fig. 3a), the complete recovery of Gd-B structure from air-dried Gd-B sample in $\mathrm{MeOH}$ vapor is a kinetic process that requires a period of hours. This is also reflected in the continuous $\mathrm{MeOH}$ sorption tests in Fig. 5b, where only part of adsorbed $\mathrm{MeOH}$ participates in Gd-B reconstruction in each run of sorption owing to kinetic factor.
The $\mathrm{MeOH}$ adsorption ratio of 1:3 in air-dried Gd-B sample in 1st run (Fig. 5b) can be explained by the partial formation of borate ester at breakthrough point, rather than physical adsorption prior to Gd-B framework formation. Under vacuum treatment, borate ester is stable so that the adsorption amount of subsequent runs continuously reduces till all borate ester groups have been re-generated (after four runs). The results indicate that the restoration of air-dried Gd-B to Gd-B follows a stepwise way as demonstrated in Supplementary Fig. 11. Our combined findings on sorption tests over both air-dried and fresh Gd-B further support the reversible structure transformation of Gd-B. The cycling performance of $\mathrm{MeOH}$ adsorption-desorption of fresh Gd-B was also evaluated (Fig. 5d), which suggests no apparent adsorption capability loss for cycling usage.

It is well documented that a diverse class of MOFs and other nanoporous materials exhibit much higher $\mathrm{MeOH}$ adsorption amount, while high temperature and reduced pressure are of necessity to release $\mathrm{MeOH}$ from the parent framework ${ }^{36-41}$. In sharp contrast, $\mathrm{MeOH}$ adsorbed in iHOF of Gd-B can automatically release $\mathrm{MeOH}$ at ambient condition. Interestingly, the accommodated $\mathrm{MeOH}$ molecules in Gd-B can be directly released at ambient condition for lighting (Supplementary Movie 1) without structural collapse (Supplementary Fig. 12). It is also verified by the example that HKUST-1-adsorbed $\mathrm{MeOH}$ cannot be lighted in air, though HKUST-1 can adsorb much more $\mathrm{MeOH}$, because very little $\mathrm{MeOH}$ can be released from HKUST-1 at ambient condition. 

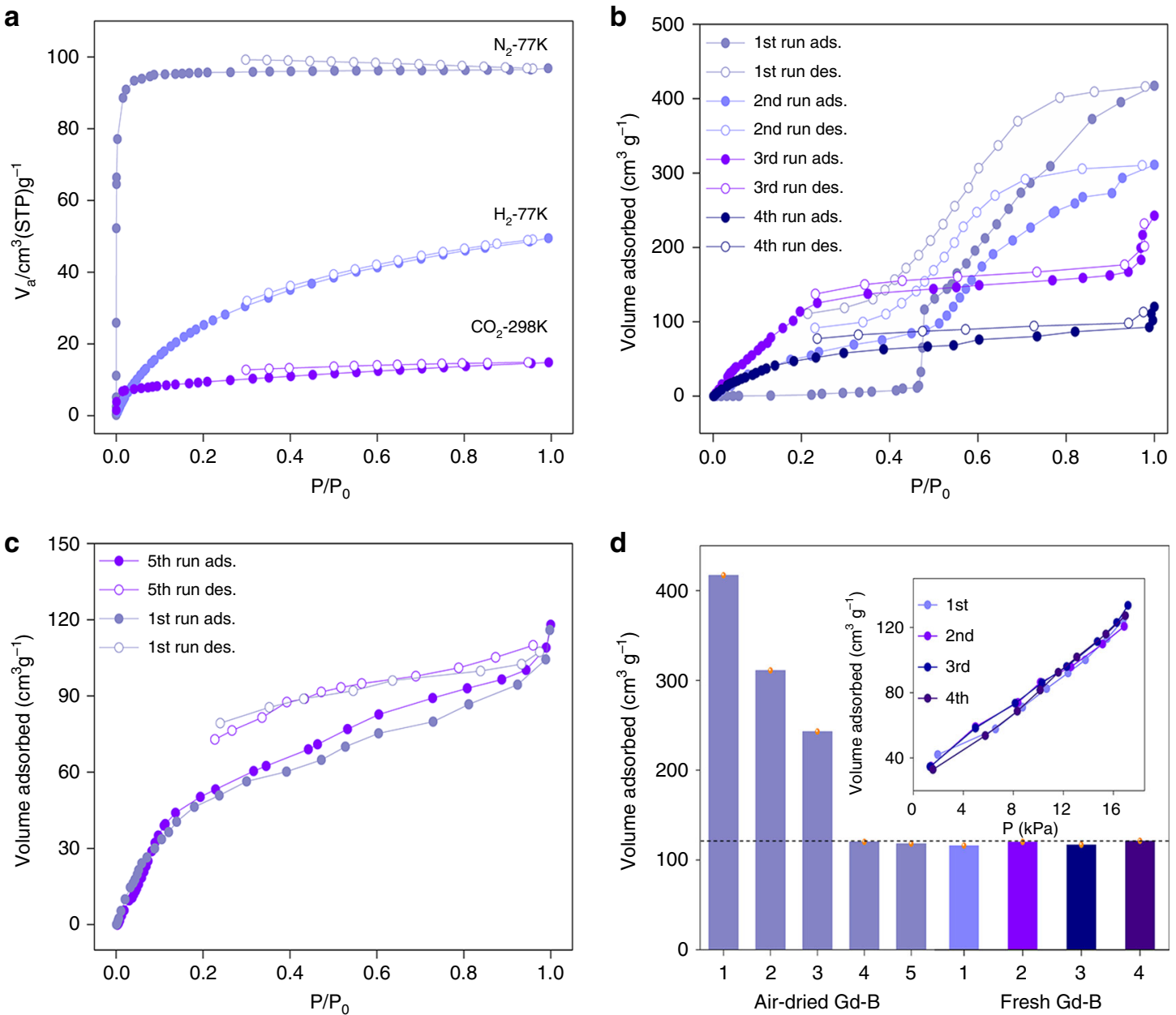

Fig. 5 Sorption behavior of fresh and air-dried Gd-B samples. a $\mathrm{N}_{2}(77 \mathrm{~K}), \mathrm{H}_{2}(77 \mathrm{~K})$, and $\mathrm{CO}_{2}(298 \mathrm{~K})$ sorption isotherms of fresh Gd-B activated by vacuum at room temperature. $\mathbf{b} \mathrm{MeOH}$ sorption isotherms over air-dried $\mathrm{Gd}-\mathrm{B}$ at $298 \mathrm{~K}$ for different runs. For each run, the sample is online activated by vacuum without exposure to air. c The fifth run of $\mathrm{MeOH}$ sorption isotherms (violet) over air-dried $\mathrm{Gd}-\mathrm{B}$ at $298 \mathrm{~K}$, together with the first run of $\mathrm{MeOH}$ sorption isotherms (gray) over fresh Gd-B treated with vacuum. $\mathbf{d}$ Cycling $\mathrm{MeOH}$ sorption performance of air-dried Gd-B and fresh Gd-B, the sorption values are denoted by orange dots. Inset: single-point $\mathrm{MeOH}$ adsorption test of fresh $\mathrm{Gd}-\mathrm{B}$, the target pressure was set as $16 \mathrm{kPa}$ according to the $\mathrm{MeOH}$ vapor pressure at $298 \mathrm{~K}$.

\section{Discussion}

Our findings reveal that metastable Gd-B is an excellent $\mathrm{MeOH}$ carrier as it captures and releases $\mathrm{MeOH}$ that accounts for about $60 \%$ of Gd-B weight, based on its automatic and reversible structural transformation at ambient condition. Intensive studies on porous frameworks have been focused and advanced on their chemical, thermal, and mechanical stability for the long-term durability towards certain applications. Relatively weak intermolecular interactions like H-bond, Van der Waals, and electrostatic forces usually lead to metastable frameworks, which are considered to be a disadvantage. However, release of the volatile organic compound (VOC) and then reuse of adsorbents require extra energy input to eliminate the guest-host interactions. Reversible structure transformation upon guest molecules adsorption and release under mild condition greatly benefits energetic material unitization, moisture capture/release. Such metastable frameworks are also potential candidates for drug delivery.

\section{Methods}

Chemicals and materials. Guanidine hydrochloride $\left(\mathrm{CN}_{3} \mathrm{H}_{5} \cdot \mathrm{HCl}, \mathrm{AR}, \geq 99.5 \%\right)$ and boric acid $\left(\mathrm{H}_{3} \mathrm{BO}_{3}, \mathrm{AR}, 99 \%\right)$ were purchased from Shanghai Macklin Biochemical Co. Ltd. (China). Methanol ( $\mathrm{MeOH}, \mathrm{AR}, \geq 99.5 \%)$ and trietrylamine
(TEA, AR, $\geq 99 \%$ ) were purchased from Sinopharm Chemical Reagent Co., Ltd. (China). Dimethyl sulfoxide- $\mathrm{d}_{6}$ was purchased from Adamas-Beta.

Characterization. Powder X-ray diffraction (PXRD) tests were carried out on a Rigaku MiniFlex 600 X-ray diffractometer using $\mathrm{Cu} \mathrm{Ka}$ radiation $(\lambda=1.54178 \AA$ ) . Elemental analyses (EA) were completed with a Vario EL III Elemental Analyzer (Elementar Inc.). The ${ }^{1} \mathrm{H}-\mathrm{NMR}$ and ${ }^{13} \mathrm{C}-\mathrm{NMR}$ spectra were recorded on a Bruker AVANCE AV III 400WB spectrometer operating at $400 \mathrm{MHz}$. Gas-sorption isotherms were measured at $77 \mathrm{~K}$ or $298 \mathrm{~K}$, and methanol vapor sorption isotherms were measured at $298 \mathrm{~K}$ on a BEL sorp-max machine, BEL, Japan.

Preparation of Gd-B single crystal. Gd-B was synthesized according to previously reported procedures (CCDC number: 1686051$)^{31}$. Briefly, $1.86 \mathrm{~g} \mathrm{CN}_{3} \mathrm{H}_{5} \cdot \mathrm{HCl}$ was dissolved in $21 \mathrm{~mL} \mathrm{MeOH}$ to form colorless solution, which was further mixed with the solution prepared by dissolving $0.6 \mathrm{~g} \mathrm{H}_{3} \mathrm{BO}_{3}$ into $24 \mathrm{~mL} \mathrm{MeOH}$ that contained $1.35 \mathrm{~mL}$ TEA. The resultant mixed solution was subjected to free standing for $12 \mathrm{~h}$ in an open vial, upon which large amount of colorless tetrahedral crystal can be obtained at room temperature. The sample was further washed with $\mathrm{MeOH}$ quickly and then collected by centrifugation at $10,000 \mathrm{rpm} / \mathrm{min}$ for $3 \mathrm{~min}$. The sample is denoted as Gd-B.

Reversible structure transformation of Gd-B. The freshly prepared Gd-B single crystal turned into wet white powder when exposed in air. The Gd-B powder $(50 \mathrm{mg})$ stored in the tube $(5 \mathrm{~mL})$ was placed into a $100-\mathrm{mL}$ beaker which con tained $30 \mathrm{~mL}$ of $\mathrm{MeOH}$ and covered by sealing film, upon which an artificial $\mathrm{MeOH}$ vapor atmosphere was created. The powder was exposed in the vapor for $24 \mathrm{~h}$ to complete the recovery process of Gd-B structure. An alternative way to 
realize the reversible structural transformation can be realized by directly dissolving $20 \mathrm{mg}$ of white powder into $0.7 \mathrm{~mL}$ of $\mathrm{MeOH}$ solvent. The tetrahedral colorless single crystals were obtained later after dissolution and recrystallization for $12 \mathrm{~h}$

Being similar with the recrystallization in $\mathrm{MeOH}, 20 \mathrm{mg}$ air-dried Gd-B was dissolved in $0.7 \mathrm{~mL}$ of $\mathrm{H}_{2} \mathrm{O}$ and subjected to recrystallization for $72 \mathrm{~h}$ under air atmosphere. This process resulted in the formation of colorless single crystal with different structure from Gd-B, which was a known structure reported by T. J. R. Weakley and named as guanidinium tetraborate dihydrate

$\left(\left[\mathrm{CN}_{3} \mathrm{H}_{6}\right]_{2}\left[\mathrm{~B}_{4} \mathrm{O}_{5}(\mathrm{OH})_{4}\right] \cdot 2 \mathrm{H}_{2} \mathrm{O} \text {, Supplementary Fig. 4, CCDC number: } 1132636\right)^{32}$. Subsequently, $20 \mathrm{mg}$ of the crystal, which was stable in air atmosphere, was grinded into white powder and dissolved in $1 \mathrm{~mL}$ of $\mathrm{MeOH}$ by gentle sonication for several minutes. The solution was then subjected to recrystallization for $24 \mathrm{~h}$ under air atmosphere, upon which Gd-B single crystal can be obtained.

MeOH sorption over air-dried and fresh Gd-B. The fresh Gd-B crystal was exposed in air for $24 \mathrm{~h}$ to transform into the powder form with no further structural change. Next, the powder (air-dried Gd-B) was subjected to vacuum for $12 \mathrm{~h}$ $\left(10^{-7} \mathrm{~Pa}\right)$ at $60^{\circ} \mathrm{C}$ prior to $\mathrm{MeOH}$ sorption test at $298 \mathrm{~K}$. To confirm the structural collapse and recovery, the air-dried Gd-B was directly subjected to multiple-run $\mathrm{MeOH}$ sorption test at $298 \mathrm{~K}$. For each run, the sample was online-activated on the sorption machine by vacuum without air interference.

The fresh Gd-B, $\left[\mathrm{B}\left(\mathrm{OCH}_{3}\right)_{4}\right]_{3}\left[\mathrm{C}\left(\mathrm{NH}_{2}\right)_{3}\right]_{4} \mathrm{Cl} \cdot 4 \mathrm{CH}_{3} \mathrm{OH}$, was vacuumed for $24 \mathrm{~h}$ $\left(10^{-7} \mathrm{~Pa}\right)$ at room temperature to initiate $\mathrm{MeOH}$ sorption test at $298 \mathrm{~K}$. The sorption result of fresh Gd-B was compared with the fifth-run sorption of air-dried $\mathrm{Gd}-\mathrm{B}$, which had completed structural recovery through four runs of $\mathrm{MeOH}$ ad/ desorption tests.

Automatic release of four guest $\mathrm{MeOH}$ molecules from bulky Gd-B. Typically, fresh $\mathrm{Gd}-\mathrm{B}$ stored in $\mathrm{MeOH}$ was collected and put onto filter paper, upon which the surface attached $\mathrm{MeOH}$ on Gd-B were removed. Subsequently, the fresh Gd-B crystal $(500 \mathrm{mg}$ ) was placed into a silica tube (length: $15 \mathrm{~cm}$, inner diameter: $10 \mathrm{~mm}$ ) and covered by sealing film. The tube was left untouched for $30 \mathrm{~min}$ to be fully filled with released $\mathrm{MeOH}$ guest molecules. A cigarette lighter was then placed at the tube outlet to ignite the released guest $\mathrm{MeOH}$ molecules from bulky Gd-B, the flame can last for few seconds (Supplementary Movie 1). After that, the sample was weighed to evaluate the mass change before and after ignition. Also, the crystal structure of Gd-B after ignition was examined by XRD.

\section{Data availability}

All data generated or analyzed during this study are included in this article and its Supplementary Information files, other data that support the findings of this study are available from the corresponding author upon request. The X-ray crystallographic coordinates for structures reported in this study have been deposited at the Cambridge Crystallographic Data Centre (CCDC), under deposition numbers 1686051 (Gd-B) and $1132636\left(\left[\mathrm{C}\left(\mathrm{NH}_{2}\right)_{3}\right]_{2}\left[\mathrm{~B}_{4} \mathrm{O}_{5}(\mathrm{OH})_{4}\right] \cdot 2 \mathrm{H}_{2} \mathrm{O}\right)$. These data can be obtained free of charge from The Cambridge Crystallographic Data Centre via www.ccdc.cam.ac.uk/ data_request/cif.

Received: 27 February 2020; Accepted: 4 June 2020;

Published online: 19 June 2020

\section{References}

1. Kumar, K. V., Preuss, K., Titirici, M. M. \& Rodríguez-Reinoso, F. Nanoporous materials for the onboard storage of natural gas. Chem. Rev. 117, 1796-1825 (2017).

2. Saha, D., Grappe, H. A., Chakraborty, A. \& Orkoulasb, G. Post-extraction separation, on-board storage, and catalytic conversion of methane in natural gas: a review. Chem. Rev. 116, 11436-11499 (2016)

3. Sloan, E. D. Fundamental principles and applications of natural gas hydrates. Nature 426, 353-359 (2003).

4. Walsh, M. R., Koh, C. A., Sloan, E. D., Sum, A. K. \& Wu, D. T. Science 326, 1095-1098 (2009).

5. Jacobson, L. C., Hujo, W. \& Molinero, V. Amorphous precursors in the nucleation of clathrate hydrates. J. Am. Chem. Soc. 132, 11806-11811 (2010).

6. Chen, L. et al. Methane hydrate formation and dissociation on suspended gas bubbles in water. J. Chem. Eng. Data 59, 1045-1051 (2014).

7. Kirchner, M. T., Boese, R., Billups, W. E. \& Norman, L. R. Gas hydrate singlecrystal structure analyses. J. Am. Chem. Soc. 126, 9407-9412 (2004).

8. Singh, D. K., Krishna, K. S., Harish, S., Sampath, S. \& Eswaramoorthy, M. No more HF: teflon-assisted ultrafast removal of silica to generate high-surfacearea mesostructured carbon for enhanced $\mathrm{CO}_{2}$ capture and supercapacitor performance. Angew. Chem. Int. Ed. 55, 2032-2036 (2016).

9. Li, Y., Li, L. \& Yu, J. Applications of zeolites in sustainable chemistry. Chem 3, 928-949 (2017).
10. Li, B., Wen, H. M., Zhou, W., Xu, J. Q. \& Chen, B. Porous metal ${ }^{-}$organic frameworks: promising materials for methane storage. Chem 1, 557-580 (2016).

11. Huang, N., Chen, X., Krishna, R. \& Jiang, D. Two-dimensional covalent organic frameworks for carbon dioxide capture through channel-wall functionalization. Angew. Chem. Int. Ed. 54, 2986-2990 (2015).

12. Kim, H. et al. Water harvesting from air with metal-organic frameworks powered by natural sunlight. Science 356, 430-434 (2017).

13. Cadiau, A. et al. Hydrolytically stable fluorinated metal-organic frameworks for energy-efficient dehydration. Science 356, 731-735 (2017).

14. Desiraju, G. R. Crystal engineering: from molecule to crystal. J. Am. Chem. Soc. 135, 9952-9967 (2013).

15. Theobald, J. A., Oxtoby, N. S., Phillips, M. A., Champness, N. R. \& Beton, P $\mathrm{H}$. Controlling molecular deposition and layer structure with supramolecular surface assemblies. Nature 424, 1029-1031 (2003).

16. Hisaki, I., Nakagawa, S., Tohnai, N. \& Miyata, M. A C C $_{3}$-symmetric macrocycle-based, hydrogen-bonded, multiporous hexagonal network as a motif of porous molecular crystals. Angew. Chem. Int. Ed. 54, 3008-3012 (2015).

17. Lin, R. B. et al. Multifunctional porous hydrogen-bonded organic framework materials. Chem. Soc. Rev. 48, 1362-1389 (2019).

18. Cai, S. et al. Hydrogen-bonded organic aromatic frameworks for ultralong phosphorescence by intralayer $\pi-\pi$ interactions. Angew. Chem. Int. Ed. 130, 4069-4073 (2018)

19. Hisaki, I. et al. Docking strategy to construct thermostable, single-crystalline, hydrogen-bonded organic framework with high surface area. Angew. Chem. Int. Ed. 57, 12650-12655 (2018).

20. Lü, J. et al. A robust binary supramolecular organic framework (SOF) with high $\mathrm{CO}_{2}$ adsorption and selectivity. J. Am. Chem. Soc. 136, 2828-12831 (2014).

21. Lü, J. \& Cao, R. Porous organic molecular frameworks with extrinsic porosity: a platform for carbon storage and separation. Angew. Chem. Int. Ed. 55, 9474-9480 (2016)

22. Chen, T. H. et al. Thermally robust and porous noncovalent organic framework with high affinity for fluorocarbons and CFCs. Nat. Commun. 5, 5131 (2014)

23. Arunan, E. et al. Definition of the hydrogen bond (IUPAC Recommendations 2011). Pure Appl. Chem. 83, 1637-1641 (2011).

24. Bao, Z. et al. Fine tuning and specific binding sites with a porous hydrogenbonded metal-complex framework for gas selective separations. J. Am. Chem. Soc. 140, 4596-4603 (2018).

25. Hu, F. et al. An ultrastable and easily regenerated hydrogen-bonded organic molecular framework with permanent porosity. Angew. Chem. Int. Ed. 56, 2101-2104 (2017)

26. Luo, X. Z. et al. A microporous hydrogen-bonded organic framework: exceptional stability and highly selective adsorption of gas and liquid. J. Am. Chem. Soc. 32, 11684-11687 (2013)

27. Adachi, A. \& Ward, M. D. Versatile and resilient hydrogen-bonded host frameworks. Acc. Chem. Res. 49, 2669-2679 (2016).

28. Horvath, D. V. et al. Polymorphism of a porous hydrogen bond-assisted ionic organic framework. CrystEngComm 20, 1779-1782 (2018).

29. Karmakar, A. et al. Hydrogen-bonded organic frameworks (HOFs): a new class of porous crystalline proton-conducting materials. Angew. Chem. $\mathbf{5 5}$ 10667-10671 (2016)

30. Abrahams, B. F. et al. Serendipity and design in the generation of new coordination polymers: an extensive series of highly symmetrical guanidinium-templated, carbonate-based networks with the sodalite topology. J. Am. Chem. Soc. 126, 2894-2904 (2004).

31. Abrahams, B. F., Haywood, M. G. \& Robson, R. Guanidinium ion as a symmetrical template in the formation of cubic hydrogen-bonded borate networks with the boracite topology. J. Am. Chem. Soc. 127, 816-817 (2005).

32. Weakley, T. J. R. Guanidinium tetraborate(2-) dihydrate, $\left(\mathrm{CH}_{6} \mathrm{~N}_{3}\right)_{2}\left[\mathrm{~B}_{4} \mathrm{O}_{5}(\mathrm{OH})_{4}\right] \cdot 2 \mathrm{H}_{2} \mathrm{O}$. Acta Crystallogr. C. C41, 377-379 (1985).

33. Mertin, B. Basic ${ }^{1} H$ - and ${ }^{13} \mathrm{C}-N M R$ Spectroscopy, first edn. (Elsevier, 2005).

34. Flaig, R. W. et al. The chemistry of $\mathrm{CO}_{2}$ capture in an amine-functionalized metal-organic framework under dry and humid condition. J. Am. Chem. Soc. 139, 12125-12128 (2017)

35. Fracaroli, A. M. et al. Metal-organic frameworks with precisely designed interior for carbon dioxide capture in the presence of water. J. Am. Chem. Soc. 136, 8863-8866 (2014).

36. Nguyen, B. T., Nguyen, H. L., Nguyen, T. C., Cordova, K. E. \& Furukawa, H. High methanol uptake capacity in two new series of metal-organic frameworks: promising materials for adsorption-driven heat pump applications. Chem. Mater. 28, 6243-6249 (2016).

37. Huang, Q. et al. A robust microporous metal-organic framework constructed from a flexible organic linker for highly selective sorption of methanol over ethanol and water. J. Mater. Chem. 22, 10352-10355 (2012). 
38. Chen, B. et al. Metal-organic framework with rationally tuned micropores for selective adsorption of water over methanol. Inorg. Chem. 47, 5543-5545 (2008).

39. Zhang, K., Zhang, L. E. \& Jiang, J. Adsorption of $\mathrm{C}_{1}-\mathrm{C}_{4}$ alcohols in zeolitic imidazolate framework-8: effects of force fields, atomic charges, and framework flexibility. J. Phys. Chem. C. 117, 25628-25635 (2013).

40. Shigematsu, A., Yamada, T. \& Kitagawa, H. Selective separation of water, methanol, and ethanol by a porous coordination polymer built with a flexible tetrahedral ligand. J. Am. Chem. Soc. 134, 13145-13147 (2012).

41. Salame, I. I. \& Bandosz, T. J. Adsorption of water and methanol on micro- and mesoporous wood-based activated carbons. Langmuir 16, 5435-5440 (2000).

\section{Acknowledgements}

We acknowledge support from Hefei National Laboratory for Physical Sciences at the Microscale, Hefei Science Center of Chinese Academy of Sciences, Fujian Institute of Innovation of Chinese Academy of Sciences, the National Natural Science Foundation of China (NSFC, 21571167, 51502282), the Fundamental Research Funds for the Central Universities (WK2060190053 and WK2060190100) and Anhui Province Natural Science Foundation (1608085MB28).

\section{Author contributions}

B.L. conceived and designed the experiments. Yang W. performed the experiments and analyzed the data. X.H. helped in the adsorption test of the samples. C.L., M.A., and Yan W. conducted parts of the mechanism analyses. N.W. helped in the NMR tests and analyses. C.C. analyzed the X-ray crystal structure of the single crystals. B.L. and Yang W. co-wrote the paper with input from all authors. All authors discussed the results and commented on the paper.

\section{Competing interests}

The authors declare no competing interests.

\section{Additional information}

Supplementary information is available for this paper at https://doi.org/10.1038/s41467 020-16976-1.

Correspondence and requests for materials should be addressed to B.L.

Peer review information Nature Communications thanks Shengqian Ma and the other, anonymous, reviewer(s) for their contribution to the peer review of this work. Peer reviewer reports are available.

Reprints and permission information is available at http://www.nature.com/reprints

Publisher's note Springer Nature remains neutral with regard to jurisdictional claims in published maps and institutional affiliations.

\section{(c) (i)}

Open Access This article is licensed under a Creative Commons Attribution 4.0 International License, which permits use, sharing, adaptation, distribution and reproduction in any medium or format, as long as you give appropriate credit to the original author(s) and the source, provide a link to the Creative Commons license, and indicate if changes were made. The images or other third party material in this article are included in the article's Creative Commons license, unless indicated otherwise in a credit line to the material. If material is not included in the article's Creative Commons license and your intended use is not permitted by statutory regulation or exceeds the permitted use, you will need to obtain permission directly from the copyright holder. To view a copy of this license, visit http://creativecommons.org/ licenses/by/4.0/.

(C) The Author(s) 2020 